\title{
ANÁLISE DA CADEIA DE VALOR EM DUAS EMPRESAS DO SETOR CALÇADISTA
}

\section{VALUE CHAIN ANALYSIS IN TWO COMPANIES OF THE SHOE SECTOR}

\author{
Luiz Carlos Schneider ${ }^{1}$; Carlos Alberto Diehl ${ }^{2}$; Peter Bent Hansen ${ }^{3}$ \\ ${ }^{1}$ Universidade do Vale do Rio dos Sinos - UNISINOS - São Leopoldo-RS - Brasil \\ schneider.luizc@gmail.com \\ ${ }^{2}$ Universidade do Vale do Rio dos Sinos - UNISINOS - São Leopoldo-RS - Brasil \\ cd@unisinos.br \\ ${ }^{3}$ Pontifícia Universidade Católica do Rio Grande do Sul - PUC - Porto Alegre-RS - Brasil \\ peter.hansen@pucrs.br
}

\begin{abstract}
Resumo
As empresas necessitam constantemente refletir sobre o tamanho de sua estrutura, ambiente de concorrência, diversificação de produtos e serviços, bem como, parcerias estratégicas, visando sua sustentabilidade no longo prazo. Dentre os vários ramos de atividade, a indústria calçadista é um dos que ao longo das últimas décadas encontra-se num alto nível de pressão competitiva. Por isto, o presente estudo tem por objetivo apresentar os modelos de integração vertical e as cadeias de valor de duas empresas de destaque no setor calçadista, para evidenciar suas diferenças $e$ abordagens estratégicas. Como resultado, identifica-se que as mesmas estabeleceram estratégias diferentes para o desenvolvimento de suas cadeias produtivas e que cada uma utilizou sua competência para criar uma vantagem competitiva no mercado onde atuam, sendo ambas reconhecidas mediante a consolidação de suas marcas no mercado nacional e internacional. A essência da construção de suas cadeias de valor, esta relacionada às diferenças na atuação destas empresas, sendo que uma tem como característica grandes volumes de venda e tecnologia proprietária na confecção de calçados sintéticos e a outra a construção e a manutenção de uma grife de calçados femininos. Pode-se afirmar que a primeira possui um maior grau de integração $e$ a segunda menor, porém ambas alcançam sucesso com essas abordagens.
\end{abstract}

Palavras-chave: integração vertical, cadeia de valor, indústria calçadista, estratégia competitiva.

\section{Introdução}

A integração das economias mundiais acelerada pelo processo de globalização, a dimensão territorial do Brasil, o crescimento da população e a conseqüente perspectiva do aumento de consumo, faz com que as empresas reflitam constantemente sobre o tamanho de sua estrutura, ambiente de concorrência, diversificação de produtos e serviços, bem como, parcerias estratégicas, para fazer frente a este ambiente. Neste cenário, as empresas repensam seus processos produtivos, administrativos, comerciais, sistemas de logística e na sua capacidade de inovação e de 
investimento, visando sua sustentabilidade no longo prazo.

As estratégias de integração vertical por parte das empresas definem de que forma elas irão atuar, quais as atividades da cadeia de valor que devem ser internalizadas e/ou externalizadas de modo que a tomada de decisão possa contribuir para a geração de valor.

Dentre os vários ramos de atividade, a indústria calçadista é um dos que ao longo das últimas décadas encontra-se num alto nível de pressão competitiva, principalmente pela importação de calçados chineses e pela concorrência com outros segmentos da indústria como a de telefones celulares. A redução de preços desses últimos produtos, a sua inserção como item de moda e o apelo comercial dos mesmos conquistou uma fatia do mercado de consumo varejista.

Também, os efeitos cambiais afetaram as empresas exportadoras. A indústria calçadista brasileira exportou em 2009, 127 milhões de pares, gerou divisas de US\$ 1,3 bilhão com as exportações que foram destinadas para mais de 140 países. Estados Unidos, Reino Unido, Argentina e Itália são os principais países importadores de calçados brasileiros. O atual parque calçadista brasileiro é formado por cerca de oito mil empresas e emprega cerca de 300 mil pessoas. Os fabricantes dispõem de máquinas, equipamentos e matérias-primas de alta qualidade para o processo de fabricação do calçado, sendo grande parte dos insumos obtida no mercado interno (ABICALÇADOS, 2010).

Neste contexto, o presente artigo tem por objetivo analisar os modelos de integração vertical e as cadeias de valor de duas empresas de destaque no setor calçadista, a fim de evidenciar suas diferenças e a eventual obtenção de vantagem competitiva por meio daquelas cadeias de valor. Essa análise pode trazer elementos que contribuam para explicar a obtenção de sucesso, mesmo por meio de estratégias diferentes de integração vertical.

O artigo será desenvolvido primeiramente abordando o referencial teórico sobre cadeia de valor e integração vertical, seguindo pelas considerações sobre a metodologia de estudo de caso, um breve histórico da indústria calçadista e, as principais características das empresas estudadas. Em seguida é realizada a discussão dos resultados, as considerações finais e, por fim, as referências.

\section{Cadeia de valor e integração vertical}

No meio empresarial, as decisões dos gestores, geralmente remetem ao objetivo de geração de valor, e estas, passam a compor um processo de formulação estratégica que irá direcionar o posicionamento das empresas visando adequá-las ao ambiente em que estão inseridas. Porém, como cita Diehl (2004 p.79) existem "limitações nos processos de formulação estratégica, geralmente de caráter conceptivo, formal e analítico, sendo necessário permitir ao processo flexibilidade". Desta forma, a flexibilização é necessária para realimentar o processo através do aprimoramento das decisões de gestão tornando-o contínuo e interativo na busca de formular estratégias específicas e 
consistentes. Além dos processos de formulação, existem os processos de implementação das estratégias, os quais são inseparáveis da estrutura, do comportamento e da cultura da companhia na qual são realizados. A Figura 1, apresenta o fluxo do processo de formulação e implementação da estratégia empresarial, segundo a concepção de Mintzberg e Quinn (2001).

Figura 1: Fluxo do processo de formulação e implementação da estratégia empresarial.

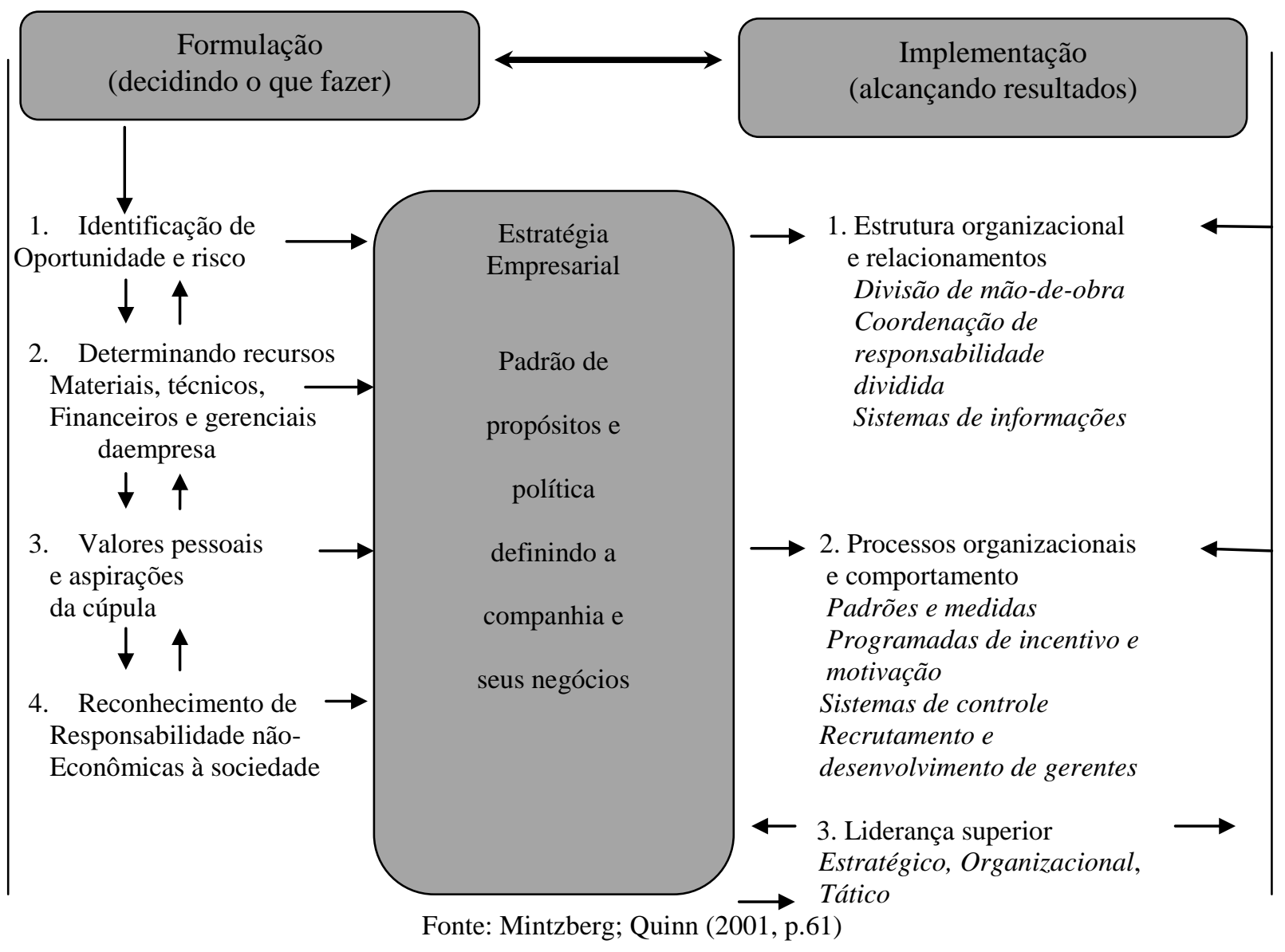

A partir do desenvolvimento da estratégia, as empresas estabelecem sua estrutura de negócio a fim de atingir aos objetivos estabelecidos, definem as atividades que serão realizadas internamente ou com parceiros externos, decidindo a formação de suas cadeias de valor e o seu grau de integração vertical ou não.

O processo estratégico da decisão de internalizar ou externalizar pode ser melhor visualizado através da árvore de decisão de produzir ou comprar conforme apresentado na Figura 2. 
Figura 2: Arvore de decisão sobre integração/ externalização

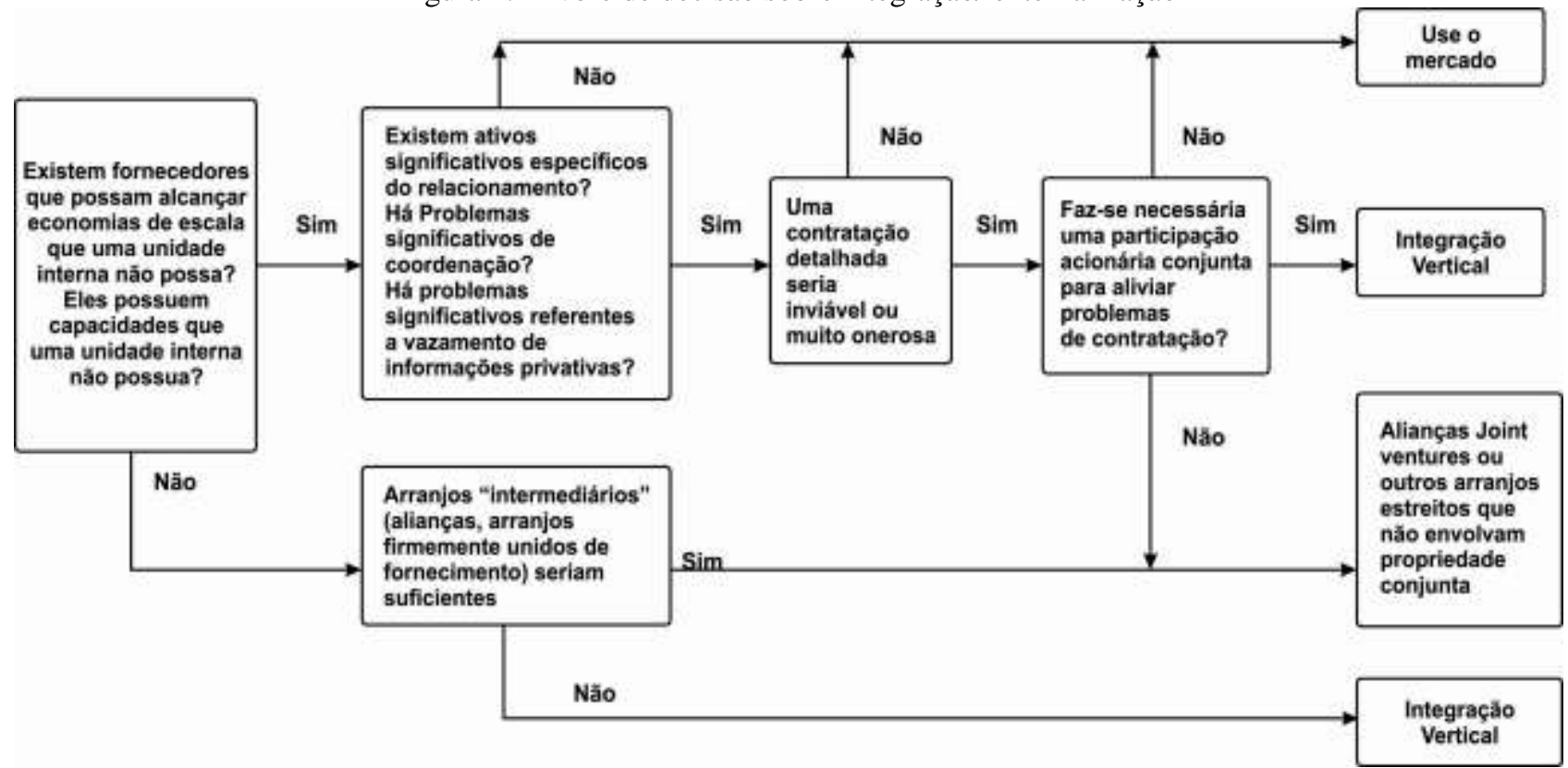

Fonte: Bezanko et al. (2007, p. 153)

De uma forma geral, o acompanhamento da execução da estratégia é realizado pela Controladoria, que assume papel importante a fim de prevenir eventuais desvios e sugerir ações que permitam atingir os objetivos estabelecidos. Nascimento e Reginato (2007, p.2) citam que:

\begin{abstract}
“A área de controladoria tem a função de promover a eficácia das decisões, monitorando a execução dos objetivos estabelecidos, investigando e diagnosticando as razões para a ocorrência de eventuais desvios entre os resultados alcançados e os esperados, indicando as correções de rumo, quando necessárias, e, principalmente, suavizando para os gestores as imponderabilidades das variáveis econômicas, através do provimento de informações sobre operações passadas e presentes e de sua adequada comunicação, de forma a sustentar a integridade do processo decisório".
\end{abstract}

Nas seções seguintes, apresenta-se referencial teórico específico relativo à cadeia de valor e integração vertical, temas objeto do presente estudo.

\title{
2.1 Cadeia de valor
}

No contexto atua o grande desafio das empresas é a busca constante pela vantagem competitiva. Para tanto, necessitam estar atualizadas em relação ao ambiente no qual estão inseridas, avaliar constantemente a estrutura de seus processos internos e externos e identificar oportunidades de otimização de seus recursos. Estas ações permitem, ao menos teoricamente, gerar vantagens para as empresas perante seus competidores. O estudo da cadeia de valor é uma das abordagens que permite identificar oportunidades de redução de custos interna e externamente, bem como possibilidades de agregação de valor ao negócio.

Diehl (2004, p. 54) cita que "a cadeia de valor é o processo pelo qual um grupo de empresas, 
operando de forma interligada adiciona valor a um produto, ao longo do processo operativo, culminando com a entrega do produto (bem ou serviço) ao consumidor, incluindo aí serviços adicionais prestados".

Hansen e Birkinshaw (2007) abordam a cadeia de valor da inovação. Estes trata-se de um processo seqüencial que se inicia pela geração da idéia, podendo acontecer nos elos internos ou externos da cadeia da empresa; a segunda fase consiste em selecionar as idéias e aperfeiçoá-las; a terceira fase é constituída pela aplicação prática destas novas idéias em produtos ou serviços para o consumidor final, e assim realimentando o processo com novos desafios, na busca de novas idéias. A cadeia de valor da inovação possibilita a criação de vantagens competitivas.

Fabe et al. (2009) citam a importância da modelagem da cadeia de valor como instrumento para analisar questões que possam indicar restrições, problemas, dificuldades e avaliar resultados oriundos de um ambiente econômico de constantes transformações. O modelo de cadeia de valor mostra o fluxo dos serviços ou produtos desde a concepção, o design ou projeto até a produção e distribuição. Enquanto cada empresa é normalmente responsável pelo sucesso do seu próprio processo de produção, no caso de um fabricante, toda a cadeia de valor contribuir para que sejam bem sucedidas a entrega do produto e a satisfação final do cliente.

O processo de aprendizagem industrial na cadeia de valores é mencionado por Puidokas et. al. (2009). O sucesso deste processo depende muito do grau de compatibilidade dos parceiros da cadeia ao longo de múltiplas dimensões que influenciam a transferência de conhecimentos e tecnologias. Os aspectos mais favoráveis à aprendizagem industrial são a semelhança dos modelos mentais, a experiência anterior no conhecimento e na transferência de tecnologia e os valores culturais parecidos. Os principais obstáculos para a aprendizagem industrial, por outro lado, são a falta de experiência em transferência de conhecimento, as relações tensas entre os parceiros de negócios, a falta de capacidade de absorção do conhecimento e um baixo nível de confiança entre as partes. A aprendizagem industrial deve ser considerada como um processo contínuo, no qual são necessários avanços das competências obtidos de forma pró-ativa (PUIDOKAS et al., 2009).

A análise da cadeia de valor desagrega uma empresa nas suas atividades estrategicamente mais relevantes, para que se possa conhecer e compreender o comportamento dos custos e das receitas de cada uma dessas atividades, a sua contribuição para o resultado final e o potencial de desenvolver vantagens competitivas em cada uma delas. Dado que a empresa não é uma entidade que desenvolve suas atividades de forma isolada dos demais agentes do ambiente, reconhece-se que a cadeia de valores de uma empresa encaixa-se em uma corrente maior de atividades, a qual Porter (1989) denominou como "sistema de valores" (BLEIL et. al., 2008). Com base neste conceito de sistema de valores, depreende-se que cada empresa pode adotar, de acordo com sua estratégia, determinado grau de integração vertical, tema abordado a seguir. 


\subsection{Integração vertical}

As empresas necessitam tomar decisões quanto às execuções de suas atividades na cadeia de valor, ou realizando internamente ou contratando terceiros para que estes efetuem. Esta decisão é denominada de decisão de produzir ou comprar. Ao realizar o processo de produzir internamente a empresa tem a gestão sobre todos os processos e internaliza as responsabilidades, ao comprar de terceiros, a empresa depende de outra empresa para execução destas atividades (BEZANKO et. al. 2007 p.125).

Quanto a integração vertical Porter (2004, p.313) cita que:

\footnotetext{
“a integração vertical é a combinação de processos de produção, distribuição, vendas e/ou outros processos econômicos tecnologicamente distintos dentro das fronteiras de uma mesma empresa. Isso representa, portanto, uma decisão da empresa no sentido de utilizar transações internas ou administrativas em vez da utilização de transações de mercado para atingir seus propósitos econômicos".
}

A decisão de comprar muitas vezes é vinculada a contratos que estabelecem cláusulas as quais têm por objetivo a proteção da operação, em termos de prazos, qualidade, confiabilidade, ou seja, proteção da operação frente às transações de mercado.

Lafontaine e Slade (2007) abordam a diferença entre integração vertical e transações de mercado: no primeiro caso a propriedade é comum e os direitos de controles são integrados entre os envolvidos; já para transações de mercado, estes são separados. Na maioria dos casos, há uma tendência de igualar operações com contratos de transações entre empresas que atuam em seu próprio interesse, contrastando com as decisões das empresas de confiar em tais operações versus integração vertical.

A integração vertical incentiva investimentos específicos e reduz os problemas da parada por interrupções operacionais, quer produtivas, administrativas ou das relações comerciais quando os mercados são imperfeitos. A integração vertical deve consequentemente, ser predominante quando for mais difícil estabelecer contratos de longo prazo entre empresas à montante e à jusante (ACEMOGLU et al., 2010).

Baily et al. (2000) afirmam que as decisões entre fazer ou comprar podem ser tomadas nos vários níveis da estrutura organizacional. As decisões tomadas nos níveis mais baixos são decorrentes de necessidades operacionais da organização e as tomadas nos níveis mais altos, por interesses táticos ou estratégicos. Dornier et al. (2000) complementam que as razões que levam à decisão de fazer versus comprar devem considerar aspectos táticos, como: (i) a redução e o controle sobre os custos de operação; (ii) disponibilizar os fundos de capitais; (iii) compensar a falta de recursos internos e (iv) melhorar a gestão de funções difíceis ou fora de controle. Também aspectos estratégicos devem ser considerados, tais como: (i) melhorar o foco do negócio; (ii) obter acesso a capacidades de nível mundial; (iii) acelerar os benefícios de reengenharia; (iv) compartilhar os 
riscos e (v) liberar recursos para outras finalidades.

Contudo, as decisões do grau de integração estão intimamente ligadas às estratégias das empresas e relacionadas com sua estrutura, ambiente de negócios e o que se pretende como geração de valor na cadeia em que a empresa estará inserida. Depende também da existência de parceiros que atendam as demandas e exigências de qualidade. Porter (2004, p.315) cita que "a integração vertical tem custos e benefícios genéricos importantes que precisam ser considerados em qualquer decisão, mas cuja relevância depende da indústria em questão".

No processo de decisão de integralizar ou externalizar atividades, os autores destacam algumas vantagens e desvantagens apresentadas no processo (veja quadro abaixo), e abordagens estas que serão utilizadas como suporte da discussão e análise dos modelos de cadeia de valores das empresas estudadas neste trabalho.

Quadro 1: Externalização: Vantagens e Desvantagens

\begin{tabular}{|c|c|c|c|}
\hline VANTAGENS & AUTORES & DESVANTAGENS & AUTORES \\
\hline Diminuição dos custos fixos & Porter & $\begin{array}{l}\text { Fortes resistências internas à } \\
\text { mudança }\end{array}$ & Pires \\
\hline $\begin{array}{l}\text { Incorporação das habilidades dos } \\
\text { fornecedores externos }\end{array}$ & Porter & $\begin{array}{l}\text { Problemas com a legislação } \\
\text { trabalhista e com sindicatos }\end{array}$ & Pires \\
\hline $\begin{array}{l}\text { Acesso às pesquisas e know-how } \\
\text { de outros fornecedores/canais }\end{array}$ & Porter & $\begin{array}{l}\text { Mensuração inadequada dos } \\
\text { custos de externalização }\end{array}$ & Pires \\
\hline $\begin{array}{l}\text { Incentivo à negociação entre as } \\
\text { partes }\end{array}$ & Porter & $\begin{array}{l}\text { Perda de controle sobre o } \\
\text { processo }\end{array}$ & Pires \\
\hline $\begin{array}{l}\text { Menor investimento em capital e } \\
\text { menores custos para superar as } \\
\text { barreiras de mobilidade }\end{array}$ & Porter & $\begin{array}{l}\text { Criação de potenciais } \\
\text { competidores }\end{array}$ & Pires \\
\hline Menores barreiras de saída & Porter & Dependência de fornecedores & Pires \\
\hline $\begin{array}{l}\text { Desenvolvimento de produtos: } \\
\text { redução de custos, prazos e acesso } \\
\text { novas tecnologias }\end{array}$ & $\begin{array}{l}\text { Mello e } \\
\text { Marx }\end{array}$ & $\begin{array}{l}\text { Redução da capacidade inovação } \\
\text { com esvaziamento da sua base } \\
\text { de conhecimento e dependência } \\
\text { tecnológica }\end{array}$ & $\begin{array}{l}\text { Mello e } \\
\text { Marx }\end{array}$ \\
\hline $\begin{array}{l}\text { Empresas de mercado podem } \\
\text { possuir informações proprietárias e } \\
\text { patentes que as habilitem a } \\
\text { produzir com custo mais baixo }\end{array}$ & $\begin{array}{l}\text { Bezanko et } \\
\text { al. }\end{array}$ & $\begin{array}{l}\text { Problemas de coordenação entre } \\
\text { os processos }\end{array}$ & $\begin{array}{l}\text { Bezanko et } \\
\text { al. }\end{array}$ \\
\hline $\begin{array}{l}\text { As empresas de mercado podem } \\
\text { estar aptas a agregar as } \\
\text { necessidades de muitas empresas } \\
\text { usufruindo assim de economias de } \\
\text { escala }\end{array}$ & $\begin{array}{l}\text { Bezanko et } \\
\text { al. }\end{array}$ & $\begin{array}{l}\text { Risco de perder o controle sobre } \\
\text { informação privativa valiosa }\end{array}$ & $\begin{array}{l}\text { Bezanko et } \\
\text { al. }\end{array}$ \\
\hline $\begin{array}{l}\text { As empresas de mercado podem } \\
\text { propiciar vantagens por sua } \\
\text { experiência de produzir para várias } \\
\text { empresas para obter economias de } \\
\text { aprendizagem }\end{array}$ & $\begin{array}{l}\text { Bezanko et } \\
\text { al. }\end{array}$ & $\begin{array}{l}\text { Custos de transação - revisões } \\
\text { de contratos, desconfiança }\end{array}$ & $\begin{array}{l}\text { Bezanko et } \\
\text { al. }\end{array}$ \\
\hline $\begin{array}{l}\text { Custos de agência = negligência } \\
\text { profissional }\end{array}$ & $\begin{array}{l}\text { Bezanko et } \\
\text { al. }\end{array}$ & $\begin{array}{l}\text { Diferenciação: a empresa pode } \\
\text { perder a oportunidade de } \\
\text { aprimorar seu produto }\end{array}$ & Porter \\
\hline
\end{tabular}




\begin{tabular}{|l|l|l|l|}
\hline & & internamente & \\
\hline $\begin{array}{l}\text { Custos de influência = influenciar } \\
\text { mercados de capital interno }\end{array}$ & $\begin{array}{l}\text { Bezanko } \text { et } \\
\text { al. }\end{array}$ & $\begin{array}{l}\text { Conhecimento patenteado: } \\
\text { abertura ao fornecedor de dados } \\
\text { patenteados que podem } \\
\text { fortalecer o mesmo na } \\
\text { negociação }\end{array}$ & Porter \\
& & \\
\hline
\end{tabular}

Fonte: Autoria própria (2010) com base em pesquisa bibliográfica

\section{Método de pesquisa}

A metodologia tem como função mostrar como andar no "caminho das pedras" da pesquisa, ajudando o pesquisador a refletir e instigar um novo olhar sobre o mundo: um olhar curioso, indagador e criativo (MENEZES; SILVA, 2001). Método é um caminho, uma forma, uma lógica de pensamento (VERGARA, 2000).

Para atingir o objetivo deste artigo, efetuou-se uma revisão bibliográfica sobre os temas estratégia, cadeia de valor e integração vertical, apresentados na seção anterior. Posteriormente foi empregada a estratégia de estudo de caso para desenvolvimento desta pesquisa, a qual teve caráter qualitativo, exploratório e descritivo.

Yin (2001) aborda que o estudo de caso representa uma investigação empírica e compreende um método abrangente, com etapas do planejamento, da coleta e da análise de dados. Pode incluir tanto estudos de caso único quanto múltiplos, assim como abordagens quantitativas menos comuns, e qualitativas de pesquisa.

A coleta de dados lançou mão da análise de documentos e de entrevistas em profundidade com roteiros semi-estruturados. A pesquisa de campo ocorreu durante os meses de junho e julho de 2010, e teve como procedimentos iniciais a pesquisa nos sites e em informações publicadas sobre as empresas. Após foi efetuado contato com as empresas, tendo sido agendadas entrevistas com pessoas que pudessem colaborar com o assunto proposto no presente estudo. A partir destas fontes, foi possível coletar os dados e informações para a elaboração da primeira versão da cadeia de valor das empresas, as quais foram remetidas para validação pelas pessoas entrevistadas. Após retorno desta versão com os devidos ajustes sugeridos pelos entrevistados, foram descritas as cadeias de valor das empresas.

Com base nestas cadeias de valor e nas demais informações colhidas durante as entrevistas (via análise de conteúdo) e na análise das informações documentais, foi possível realizar a triangulação dos dados e, posteriormente, analisar e discutir os aspectos estratégicos vinculados às cadeias de valor relacionadas com a integração e externalização de determinadas atividades produtivas das empresas estudadas. Este abordagem é apresentada na seção 5 adiante.

\section{Características das empresas do presente estudo}


As empresas do presente estudo fazem parte do ramo calçadista.

O processo de desenvolvimento desta indústria no estado do Rio Grande do Sul teve inicio em junho de 1824 com a chegada dos primeiros imigrantes alemães. Com o processo inicial totalmente artesanal e que atendia a demanda inicial, foi ao longo do tempo se modificando, surgindo os primeiros curtumes, o desenvolvimento de algumas máquinas para fins específicos de produção de calçados (ABICALÇADOS, 2010).

Com a evolução do consumo e a necessidade de atender a esta demanda, evoluíram os processos de produção, passando estes a serem automatizados. Surgem então as primeiras fábricas de calçados no Vale do Rio dos Sinos. Em 1968 é realizada a primeira exportação de calçados através da empresa Strassburger com destino aos Estados Unidos. A partir daí, abre-se o mercado externo para o calçado brasileiro com contatos realizados diretamente pelos importadores (ABICALÇADOS, 2010).

O Brasil atualmente é um dos países de destaque na fabricação de calçados, por produzir calçados com design, qualidade e preços competitivos para os mercados interno e externo (ABICALÇADOS, 2010).

As empresas pesquisadas no presente estudo estão entre as maiores do segmento de calçados. A empresa Grendene S/A é considerada uma das maiores produtoras de calçados sintéticos do mundo e a empresa Arezzo S/A, por sua vez, é considerada a maior marca de varejo de calçados femininos fashion da América Latina. Nas seções seguintes serão apresentadas as principais características das referidas empresas.

Para o desenvolvimento da análise proposta neste trabalho foi necessário o estudo dos principais processos das empresas pesquisadas visando entendimento de suas cadeias de valor, o que permitiu a montagem dos modelos apresentados nas Figuras 3 e 4 na seção 5, a qual trata da análise dos dados. A partir disto, efetuou-se a análise do grau de integração tendo como base as vantagens e desvantagens do processo de externalização apresentados no Quadro 1, cruzando-as características das cadeias de valores das empresas.

\subsection{Principais características da empresa Grendene S/A}

A Grendene S/A empresa gaúcha do setor de calçados fundada em 1971 tem como principal diferencial a tecnologia própria na produção de calçados sintéticos, tronou-se uma das maiores produtoras mundiais deste tipo de calçado. Empresa totalmente integrada possui fábricas próprias inclusive para a produção de seu principal insumo o PVC (Policloreto de Vinila) e de moldes para injeção de seus calçados. Sua logística de distribuição atinge os mercados nacional e exterior através de distribuidores e varejistas. (GRENDENE, 2010).

A empresa construiu ao longo do tempo marcas de sucesso, como Melissa, Rider, Grendha, 
Ipanema e Ilhabela. Adota parcerias estratégicas com personagens de sucesso como Gisele Bündchen que originou a marca Ipanema GB (GRENDENE, 2010).

Suas unidades industriais estão concentradas no Estado do Ceará, onde em 1990 iniciou suas atividades de produção naquele Estado. No Estado do Rio Grande do Sul, mantém unidades de desenvolvimento de produtos, produção de amostras e as áreas administrativas de apoio como Vendas, Marketing, Controladoria, TI e Suprimentos. No exterior atua com duas empresas que atendem diretamente os clientes dos Estados Unidos e Argentina bem como, por exportações diretas (GRENDENE, 2010).

\subsection{Principais características da empresa Arezzo S/A}

A atual empresa Arezzo S/A, também é uma empresa gaúcha de destaque no segmento de calçados, com uma marca forte construída a partir de 1972 quando da sua fundação que teve como concepção a alta qualidade e design contemporâneo. Em 2007 nasceu a Arezzo S/A, companhia resultante da união das empresas Arezzo e Schutz, ambas pertencentes ao mesmo segmento de mercado. A combinação de Arezzo e Schutz teve como objetivo atingir uma escala de atuação mais robusta nos mercados nacional e internacional, mantendo a independência e a personalidade das marcas (AREZZO, 2010).

No início de novembro de 2007, A Tarpon Investiment Group, gestora de recursos, anunciou a aquisição por intermédio de seu fundo Tarpon All Equities de participação acionária de $25 \%$ da Arezzo S/A. O objetivo desta aquisição foi de lançar as bases para a criação de uma empresa ainda mais forte e arrojada, líder absoluta em nichos diferenciados do mercado de varejo de moda (AREZZO, 2010).

São quatro os focos da Arezzo: tecnologia de ponta, pesquisa, design e satisfação do consumidor. A consumidora-alvo da griffe é a mulher contemporânea, conhecedora de moda e ciente da importância da imagem no mundo atual (AREZZO, 2010).

A produção da marca é inteiramente terceirizada nas melhores empresas calçadistas do Brasil, o qual hoje se encontra entre os sete maiores países fabricantes de calçados no ranking internacional (AREZZO, 2010).

Atualmente, a rede de franquias Arezzo possui 250 lojas distribuídas em mais de 113 municípios e presentes em todos os Estados Brasileiros, com $\mathrm{R} \$ 400$ milhões de faturamento anual; 3 milhões em média de produtos vendidos por ano e 1 milhão de clientes cadastrados (AREZZO, 2010).

\section{Análise dos dados}

A seguir serão apresentados a análise dos dados e os aspectos estratégicos vinculados às 
cadeias de valor relacionadas com a integração e externalização de determinadas atividades produtivas das empresas estudadas.

\subsection{Cadeia de valor - Grendene S/A}

Na Figura 3 a seguir é apresentada, de forma esquemática, a cadeia de valor da Grendene. Na cadeia de valor da Grendene o fabricante é interno, com fábricas especializadas em tipos diferentes de componentes, calçados e moldes de injeção/pintura. A parte de desenvolvimento de produtos também é realizada internamente. O controle sobre o fornecimento de insumos é efetuado pela empresa que os adquire de terceiros.
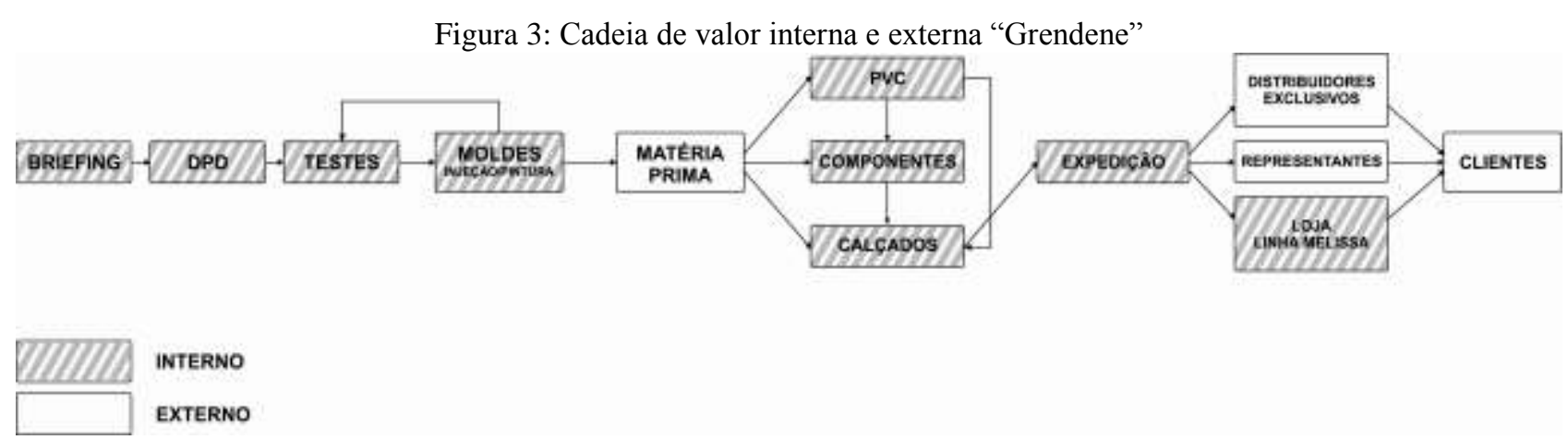

Fonte: Autoria própria com base me pesquisa documental e entrevistas (2010)

No desenho de sua cadeia de valor o processo inicia-se pelo briefing, etapa onde se efetua a coleta dos dados e cria-se um roteiro de ação visando à prospecção de novos produtos para a etapa seguinte de desenvolvimento. O briefing é considerado um processo relevante para a elaboração de uma proposta de pesquisa de mercado. Na etapa de desenvolvimento é efetuada a concepção dos produtos, os testes e a confecção das matrizes/moldes. Nesta etapa, o produto é testado exaustivamente até receber a aprovação para entrar em linha de produção.

A parte de suprimentos possui estrutura própria, que adquire as matérias-primas de terceiros. São utilizadas na produção, entre outros, o insumo principal o PVC - poli cloreto de vinila que é um plástico não $100 \%$ originário do petróleo. Na sequencia da cadeia de valor, tem-se a produção dos componentes para a fabricação dos calçados e posteriormente sua montagem, etapas estas realizadas internamente à empresa.

Após, os calçados são organizados na expedição interna para serem destinados aos clientes e aos distribuidores exclusivos. Na cadeia de valor também existem lojas próprias para uma linha de calçados denominada loja Melissa. Portanto, a cadeia de valor da empresa, como consta em seu próprio sitio na internet (www.grendene.com.br), é considerada totalmente verticalizada. A seguir resume-se o significado de cada etapa da cadeia de valor da Grendene apresentada na Figura 3:

- Briefing: etapa de coleta de tendências do mercado da moda que visa à prospecção de 
novos produtos, esta atividade é realizada por uma área de gestão de portfólio e produtos;

- Desenvolvimento de Produtos: a partir das tendências repassadas pelo briefing, a área de desenvolvimento de produtos inicia o processo de criação e estudo de materiais;

- Testes: os produtos são produzidos e testados em fábricas específicas para testes;

- Moldes: após aprovação do produto, inicia-se a produção dos moldes em fábrica específica e própria;

- Matéria-Prima: a área de suprimentos desenvolve novos materiais e mantém carteira de fornecedores externos de matérias-primas, com os quais negocia volumes, preços e prazos de entrega;

- PVC: fábrica interna de produção de PVC - policloreto de vinila, que abastece as fábricas de calçados injetados;

- Componentes: fábrica interna de produção de componentes para calçados montados;

- Calçados: fábricas interna de produção de calçados injetados;

- Expedição: etapa interna de armazenamento de calçados destinada a expedir a produção aos clientes;

- Distribuidores exclusivos: distribuidores externos exclusivos da Grendene;

- Representantes: representantes comerciais externos que atuam na venda de calçados;

- Loja linha Melissa: lojas próprias exclusivas da linha melissa;

- Clientes: consumidor final atendido por distribuidores exclusivos, representantes e loja própria Melissa.

Na seção seguinte será apresentada e analisada a cadeia de valor da empresa Arezzo S/A.

\subsection{Cadeia de valor - Arezzo S/A}

Na Figura 4 a seguir apresenta-se a cadeia de valor da empresa Arezzo. A cadeia de valor da empresa tem a maioria das etapas realizadas externamente, onde o agente de produção efetua a interface entre a empresa e os fabricantes a fim de suprir a demanda buscando a qualidade e custos competitivos. O fornecimento das matérias-primas também tem a participação dos agentes de produção e é realizado por terceiros. Na etapa de distribuição a empresa utiliza operadores logísticos que são responsáveis por armazenar e distribuir os produtos aos franqueados. Estes, têm como fornecedor único a Arezzo e atendem o consumidor final dentro dos padrões exigidos pela empresa. 
Figura 4: Cadeia de valor interna e externa "Arezzo"

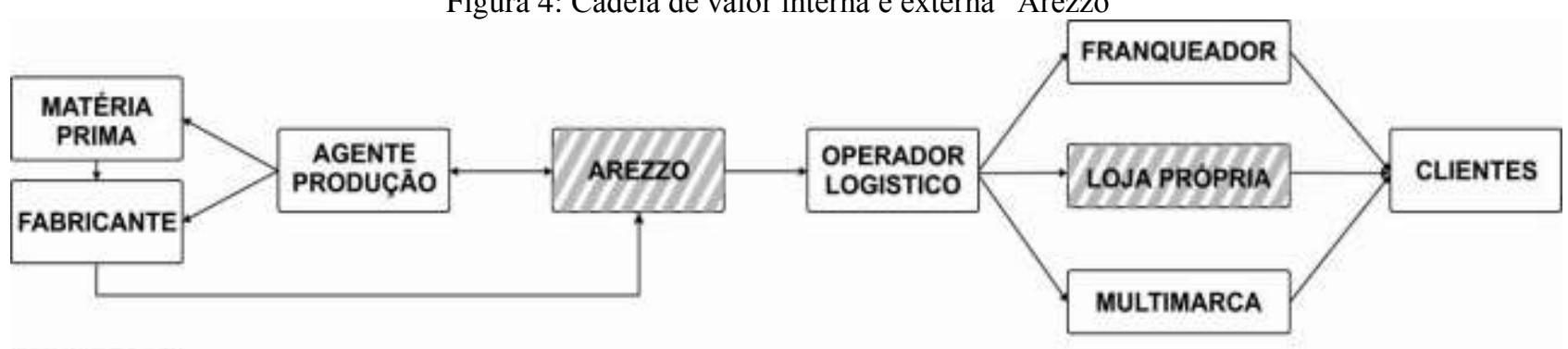

\section{INTERNO}

EXTERNO

Fonte: Autoria própria com base em pesquisa documental e entrevistas (2010)

As lojas próprias funcionam como as franqueadas, mas atuam como modelo para as demais. As lojas multimarcas atuam em praças sem franquias comprando diretamente da Arezzo. As principais fontes de receitas da empresa Arezzo advêm dos royalties e da revenda dos produtos. A cadeia de valor da empresa tem como característica principal a externalização. A seguir descreve-se o significado de cada etapa da cadeia de valor da Grendene apresentada na Figura 4:

- Matéria-Prima: fornecedores externos de matérias-primas que são contratados mediante atuação do agente de produção externo;

- Fabricantes: fábricas externas de produção de calçados que são contratadas por agente externo e que atendem as premissas estabelecidas pela Arezzo;

- Agente de produção: empresas externas que efetuam a interface entre a Arezzo e os fabricantes e fornecedores;

- Arezzo: empresa que empresta seu nome a marca de varejo de calçados femininos;

- Operador logístico: empresas externas responsáveis por armazenar e distribuir os produtos;

- Franqueador: empresas externas que vendem produtos exclusivos da marca Arezzo;

- Loja própria: lojas próprias exclusivas da empresa Arezzo;

- Multimarca: empresas e lojas externas que atuam em praças sem franquias Arezzo comercializando os produtos da marca;

- Clientes: consumidor final atendido por franquias, lojas próprias ou multimarcas.

Na seção seguinte, apresenta-se uma análise dos modelos de cadeias de valor de ambas as empresas estudadas no presente estudo.

\subsection{Análise das cadeias de valor das empresas}

Ao analisar as cadeias de valor das duas empresas do segmento de calçados, identifica-se 
que elas optaram por modelos diferentes de cadeias de valor. O modelo da Grendene é verticalizado ou integrado enquanto o modelo da Arezzo é externalizado ou desintegrado. Porém, é oportuno destacar que as empresas têm focos de negócio diferentes, onde uma possui como característica grandes volumes de venda e tecnologia proprietária na confecção de calçados sintéticos e a outra tem como foco a construção e a manutenção de uma grife de calçados femininos. Essa distinção possibilita estabelecer a essência estratégica, considerada na construção de suas cadeias de valor.

A construção de cadeia de valor diferenciada entre empresas tem relação com seu negócio. Identifica-se que uma das empresas, por produzir e vender grandes volumes de calçados e ter tecnologia única, teria dificuldades na formação de elos externos que tivessem a capacidade de atender as características e a demanda deste negócio, em termos de volumes, custos competitivos e tecnologia. Neste sentido Acemoglu et al. (2010) citam que a integração vertical tende, consequentemente, a ser mais predominante quando é mais difícil estabelecer contratos de longo prazo entre empresas à montante e à jusante da cadeia. Então a opção de internalizar parece coerente com estas características.

Por outro lado a externalização conforme cita Puidokas et al. (2009), possibilita o desenvolvimento da aprendizagem industrial na cadeia de valor tendo como os aspectos mais favoráveis a semelhança dos modelos mentais, a experiência anterior no conhecimento e na transferência de tecnologia e da proximidade cultural.

Naturalmente, qualquer que seja a opção da empresa pela externalização ou não, existem vantagens e desvantagens dessa escolha.

Para permitir uma análise das vantagens e desvantagens que estas diferentes estratégias de cadeias de valor identificadas apresentam, desenvolve-se a seguir um quadro-resumo da situação de cada empresa tendo como base o Quadro 1 do referencial teórico.

O Quadro 2, descreve as possíveis vantagens e desvantagens que a Grendene possui ao adotar a cadeia de valor verticalizada.

Quadro 2: Vantagens e desvantagens na estratégia de cadeia de valor da Grendene

\begin{tabular}{|l|l|}
\hline \multicolumn{1}{|c|}{ VANTAGENS } & \multicolumn{1}{|c|}{ DESVANTAGENS } \\
\hline $\begin{array}{l}\text { Menos exposição a problemas de legislação } \\
\text { trabalhista e previdenciária }\end{array}$ & $\begin{array}{l}\text { Custos de agência = negligência profissional } \\
\text { pela estrutura interna formada que pode levar a } \\
\text { certa acomodação }\end{array}$ \\
\hline $\begin{array}{l}\text { Conhecimento da estrutura de seus custos em } \\
\text { toda a cadeia de valor }\end{array}$ & $\begin{array}{l}\text { Custos de influência = influenciar mercados de } \\
\text { capital interno quanto às tecnologias e } \\
\text { conhecimentos técnicos desenvolvidos } \\
\text { internamente }\end{array}$ \\
\hline $\begin{array}{l}\text { Diferenciação: agilidade no processo de } \\
\text { desenvolvimento e criação de novos produtos e } \\
\text { tecnologias que inicialmente serão de domínio } \\
\text { interno }\end{array}$ & $\begin{array}{l}\text { Maior investimento em capital e estrutura maior } \\
\text { de custos fixos }\end{array}$ \\
\hline Aumento de sua capacidade de inovação com a & Maior dependência do capital intelectual interno \\
\hline
\end{tabular}




\begin{tabular}{|l|l|}
\hline criação de uma base de conhecimento & para inovações \\
\hline $\begin{array}{l}\text { Domínio e controle sobre informações } \\
\text { estratégicas do negócio }\end{array}$ & $\begin{array}{l}\text { Custos maiores com processos internos que } \\
\text { podem interferir no ponto de equilíbrio }\end{array}$ \\
\hline Controles sobre os processos & $\begin{array}{l}\text { Menos acesso a empresas de mercado que } \\
\text { possuem informações proprietárias e patentes }\end{array}$ \\
\hline $\begin{array}{l}\text { Menor dependência de terceiros que podem } \\
\text { afetar atendimento à demandas }\end{array}$ & \\
\hline
\end{tabular}

Fonte: Autoria própria com base em pesquisa de campo (2010)

A seguir o Quadro 3 destaca algumas vantagens e desvantagens da Arezzo ao adotar seu modelo de cadeia de valor.

Quadro 3: Vantagens e desvantagens na estratégia de cadeia de valor da Arezzo

\begin{tabular}{|c|c|}
\hline VANTAGENS & DESVANTAGENS \\
\hline $\begin{array}{l}\text { Incorporação das habilidades dos } \\
\text { fornecedores/canais externos }\end{array}$ & $\begin{array}{l}\text { Mensuração inadequada dos custos de } \\
\text { externalização }\end{array}$ \\
\hline $\begin{array}{l}\text { Abertura do acesso às pesquisas e know-how de } \\
\text { outros fornecedores/canais }\end{array}$ & $\begin{array}{l}\text { Dependência de fornecedores e terceiros } \\
\text { (agentes de produção) }\end{array}$ \\
\hline $\begin{array}{l}\text { As empresas de mercado podem estar aptas a } \\
\text { agregar as necessidades de muitas empresas } \\
\text { usufruindo assim economias de escala }\end{array}$ & $\begin{array}{l}\text { Redução da capacidade de inovação com } \\
\text { esvaziamento da sua base de conhecimento e } \\
\text { dependência tecnológica }\end{array}$ \\
\hline $\begin{array}{l}\text { As empresas de mercado podem propiciar } \\
\text { vantagens por sua experiência de produzir para } \\
\text { várias empresas para obter economias de } \\
\text { aprendizagem }\end{array}$ & Problemas de coordenação entre os processos \\
\hline $\begin{array}{l}\text { Redução custos de agência }=\text { negligência } \\
\text { profissional pela estrutura interna formada que } \\
\text { pode levar a certa acomodação }\end{array}$ & $\begin{array}{l}\text { Risco de perder o controle sobre informação } \\
\text { privativa valiosa }\end{array}$ \\
\hline $\begin{array}{l}\text { Redução custos de influência }=\text { influenciar } \\
\text { mercados de capital interno quanto às } \\
\text { tecnologias e conhecimentos técnicos } \\
\text { desenvolvidos internamente }\end{array}$ & $\begin{array}{l}\text { Custos de transação - revisões de contratos, } \\
\text { desconfiança, aumento de custos e de riscos à } \\
\text { operação }\end{array}$ \\
\hline $\begin{array}{l}\text { Menor investimento em capital e menores } \\
\text { custos para superar as barreiras de mobilidade }\end{array}$ & $\begin{array}{l}\text { Desenvolvimento de produtos: por depender de } \\
\text { terceiros pode ser mais lenta as repostas ao } \\
\text { mercado da moda, no que tange a } \\
\text { desenvolvimento, testes, aprovações. }\end{array}$ \\
\hline & $\begin{array}{l}\text { Desenvolvimento tecnológico: dependência de } \\
\text { terceiros }\end{array}$ \\
\hline
\end{tabular}

Fonte: Autoria própria com base em pesquisa de campo (2010)

A cadeia de valor de ambas as empresas denota que seus objetivos são diferentes e que estes têm relação com o processo estratégico de decisão do que estas pretendem para seus negócios. Utiliza-se a seguir a árvore de decisão sobre integração vertical de Bezanko et al. (Figura 2) para comparar as opções das empresas. 
Figura 5: Árvore de decisão da Grendene

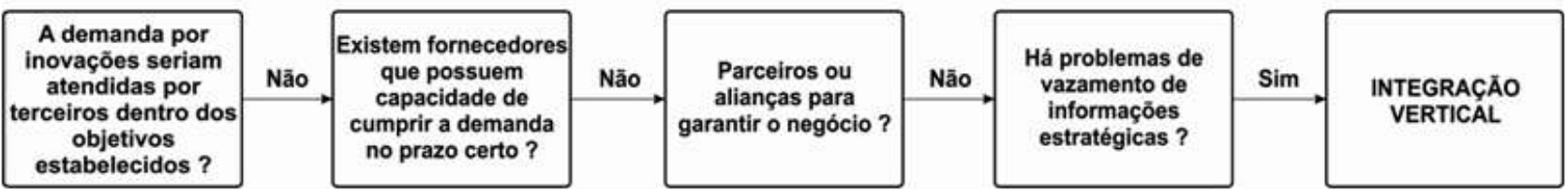

Fonte: Adaptado de Bezanko et al. (2007, p.153)

A Grendene, pela estratégia adotada em seu negócio, trabalha com grandes volumes e possui tecnologia proprietária e exclusiva na produção de calçados à base de PVC (Policloreto de Vinila). Assim, tem dificuldades de encontrar parceiros externos que possam atender ao seu formato de negócio. Desta forma, a Figura 5 mostra que a empresa opta por criar ambientes internos que tenham a capacidade de atender as demandas e características competitivas do negócio, criando elos internos de geração de valor.

Figura 6: Árvore de decisão da Arezzo

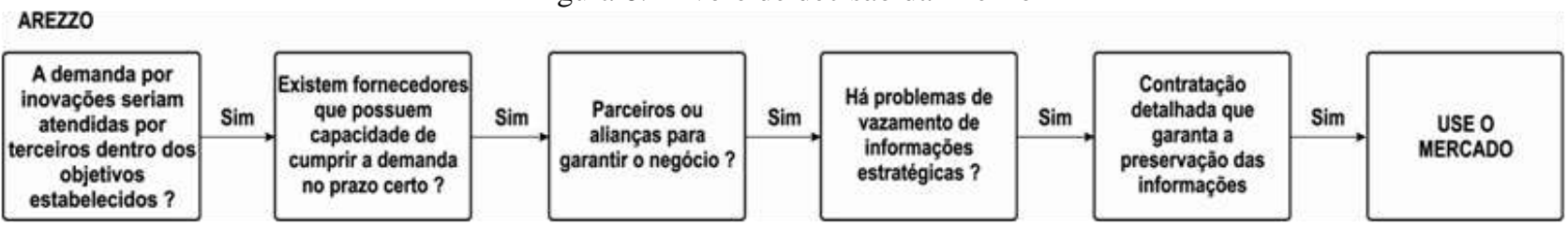

Fonte: Adaptado de Bezanko et al. (2007, p.153)

A Arezzo é considerada a maior marca de varejo de calçados femininos fashion da América Latina, reunindo conceito, alta qualidade e design contemporâneo. Seu foco não está concentrado em tecnologia proprietária ou na entrega de grandes volumes como a Grendene. Sua árvore de decisão conforme Figura 6, recai sobre a opção de utilizar parceiros externos especialistas e exclusivos e procura mitigar os riscos de vazamento de informações estratégicas efetuando contratação detalhada e criando parcerias que garanta a preservação das mesmas (BEZANKO et al., 2007).

Contudo, em ambas as estruturas de cadeia de valor analisadas mostra-se propício o processo de aprendizagem industrial. Para que esse processo surta efeito deve transpor certos obstáculos como a falta de experiência em transferência de conhecimento, as relações tensas entre os parceiros de negócios, a falta de capacidade de absorção de tecnológica, processos técnicos e um baixo nível de confiança. Assim, a aprendizagem industrial deve ser considerada como um processo contínuo, no qual são necessários avanços das competências obtidos de forma pró-ativa (PUIDOKAS et al., 2009).

Por fim nesta análise da cadeia de valor das empresas, cabe salientar o tema inovação que possibilita a criação de vantagens competitivas para as mesmas. Esse tema está presente entre os processos realizados internamente ou externamente nos elos da cadeia, independente do grau de verticalização. Para fomentar este processo deve-se valorizar a geração de idéias e adotar um 
processo sequencial a fim de selecioná-las, desenvolvê-las em serviços ou produtos e difundí-las em práticas, serviços ou produtos (HANSEN et al., 2007). Isto pode ser obtido através de ações integradas entre áreas, com projetos de incentivo à inovação, onde as pessoas são estimuladas a gerar idéias sobre novos produtos, otimização de processos, e, gradualmente, esta ação pode ser institucionalizada na empresa passando a fazer parte de sua cultura. Desta forma, também pode-se considerar que estas empresas disseminam em suas cadeias de valor a necessidade de inovação constante, em função do mercado onde atuam, forte concorrência e a necessidade de atender seus públicos com produtos diferenciados em tecnologia e design.

\section{Considerações finais}

A indústria calçadista, como outros ramos da atividade empresarial encontra-se ao longo das últimas décadas num alto nível de pressão competitiva. Para fazer frente a este cenário, as empresas deste segmento necessitam gerir adequadamente suas cadeias de valor e reconhecer as dos competidores, permitindo visualizar oportunidades que possam gerar vantagem competitiva.

O processo de configuração da cadeia de valor das empresas está intrinsecamente vinculado ao modelo de negócio que as mesmas pretendem implantar. No presente estudo, tendo se pesquisado os modelos de integração vertical e as cadeias de valor de duas empresas de destaque no setor de calçados, foi possível evidenciar esta relação. Percebeu-se que uma delas tem como característica grandes volumes de venda e tecnologia proprietária na confecção de calçados sintéticos e a outra a construção e a manutenção de uma griffe de calçados femininos. Ambas, cada qual à sua forma adequaram seu modelo de cadeia de valor ao seu negócio e às características e requisitos competitivos do mesmo.

Ao estabelecerem estas estratégias para o desenvolvimento de suas cadeias de valor, cada empresa contribuiu com sua competência central para criar uma vantagem competitiva no mercado onde atua e agregar valor ao cliente, mercado este que reconhece estas empresas através da consolidação de suas marcas no mercado nacional e internacional.

A partir deste estudo foi possível relacionar as evidências de estratégias competitivas das cadeias de valor diferenciadas do presente estudo, às competências intrínsecas de ambas as empresas.

Outros estudos podem ser realizados no mesmo segmento, ou em outros segmentos, para verificar se as estratégias diferenciadas das empresas geram margens líquidas distintas e se a externalização de atividades não é um fator limitante ao crescimento das empresas.

\section{Abstract}


The companies constantly need to reflect on the size of its structure, environment of competition, diversification of products and services, as well as, strategical partnerships, aiming at its support in the long stated period. Amongst some types of activity, the footwear industry is one of that, throughout the past decades, meets in one high level of competitive pressure. Therefore, this study aims to present the models of vertical integration and value chains of two outstanding companies in the footwear sector, to highlight their differences and strategic approaches. As a result, it identifies that they have established different strategies to develop their supply chains and each one has used its power to create a competitive advantage in markets where they operate and are both recognized by consolidating their brands nationally and internationally. The essence of the construction of their value chains, is related to differences in the performance of these companies, with a haracteristically large amounts of sales and proprietary technology in the manufacture of synthetic shoes and other construction and maintenance of a brand of women's shoes. It can be stated that the first company has a higher degree of integration and second company lower, but both achieve success with these approaches.

Key-words: vertical integration; value chain; footwear industry; competitive strategy.

\section{Referências}

ABICALÇADOS. Institucional: Histórico. Disponível em: 〈http://www.abicalcados.com.br>. Acesso em: 07 jul. 2010.

ACEMOGLU, D; JOHNSON, S; MITTON, T. Determinants of Vertical Integration: Financial Development and Contracting Costs. The Journal Of Finance. V. LXIV nº 3. Junho 2009.

AREZZO S/A. Empresa: Arezzo. Disponível em: <http://www.arezzo.com.br>. Acesso em: 02 jun. 2010.

BAILY, P. et al. Compras: Princípios e Administração. Tradução Ailton Bomfim Brandão. São Paulo: Atlas, 2000.

BESAnKo, D.; BRAEUTIGAM, R. R. Microeconomia uma Abordagem Completa. Rio de Janeiro: LTC, 2004.

BEZANKO, D. et al. A Economia da Estratégia. Porto Alegre: Bookman Companhia Editora, 2007.

BLEIL, C.; SOUZA, M. A.; DIEHL, C. A. Mensuração Econômica da Cadeia Interna de Valor do Segmento

Madeireiro de Pinus: Um Estudo de Caso. Gestão \& Regionalidade - Vol. 24 - No 70 - mai-ago/2008.

DIEHL, C. A. Controle Estratégico de Custos: um modelo referencial avançado. Tese de Doutorado, UFSC, 2004.

DORNIER, P. P. et al. Logística e Operações Globais: textos e casos. São Paulo: Atlas, 2000.

EISENHARDT, K. M. Building Theories from Case Study Research. Academy of Management Review. v. 14, (4), p. 532-550, 1989.

cross ${ }^{\text {ref }}$

FABE, A.; ULRIKE, G.; ETTI, W. Value Chain Analysis Methodologies in the Context of Environment and Trade Research. Gottfried Leibniz University of Hannover, Institute for Environmental Economics and World Trade. P.429. September/2009.

GRENDENE S/A. Relações com Investidores: A Empresa. Disponível em: 〈http:// www.grendene.com.br〉. Acesso em: 02 jun. 2010.

HANSEN, M.T.; BIRKINSHAW, J. The Innovation Value Chain. Harvard Business Review. June, 2007.

LAFONTAINE, F.; SLADE, M. Vertical Integration and Firm Boundaries: The Evidence. Journal of Economic Literature. May, 2007.

MELLO, A.M; MARX, R. Manutenção da Capacidade Inovadora na Externalização do Desenvolvimento De Produtos: o caso da indústria automobilística. Revista Gestão Industrial, v. 02, n. 04, p. 01-12, 2006. 
MENEZES, E. M.; SILVA, E. L. Metodologia da Pesquisa e Elaboração de Dissertação. UFSC/PPGEP/LED, 2001, Florianópolis.

MINTZBERG, H; QUINN, J. B. O Processo da Estratégia. 3. ed. Porto Alegre: Bookman, 2001.

NASCIMEnTO, A. M.;REGINATO, L. Controladoria: um enfoque na eficácia organizacional. São Paulo: Atlas, 2007.

PIRES, S. R. I. Gestão da Cadeia de Suprimentos: conceitos, estratégias, práticas e casos. São Paulo: Atlas, 2004.

PORTER, M. E. Vantagem Competitiva: criando e sustentando um desempenho superior. Rio de Janeiro: Campus, 1989.

Estratégia Competitiva. Rio de Janeiro: Campus, 2004.

PUIDOKAS, K.; JUCEVICIUS, G. The Inter-Organizational Industrial Learning of Lithuanian Furniture Manufacturers in the Value Chain of the Baltic Sea Region. Kaunas University of Technology. 2009. Nr.3 (65).

VENTURA, M. M. O Estudo de Caso como Modalidade de Pesquisa. Revista SOCERJ. 2007; 20 (5):383-386 -

Setembro/Outubro.

VERGARA, S. C. Projetos e Relatórios de Pesquisa em Administração. 3. ed. São Paulo: Atlas, 2000.

YIN R. K. Estudo de caso: planejamento e métodos. Tradução Daniel Grassi. 2. ed. Porto Alegre: Bookman, 2001.

\section{Dados completos dos autores:}

Nome completo: Luiz Carlos Schneider

Filiação institucional: Faculdade dos Imigrantes - FAI

Departamento: Ciências Contábeis

Função ou cargo ocupado: Professor

Endereço completo para correspondência (bairro, cidade, estado, país e CEP)

Cidade: Farroupilha, Bairro: PIO X, Estado: Rio Grande do Sul, CEP: 95180-000, Pais: Brasil

Telefones para contato: (54) 3268-5178 e (54) 9903-3567

e-mail: schneider.luizc@gmail.com

Nome completo: Carlos Alberto Diehl

Filiação institucional: Programa de Pós-Graduação em Ciências Contábeis (PPGCont) da

Universidade do Vale do Rio dos Sinos (UNISINOS)

Departamento: Unidade Acadêmica de Pesquisa e Pós-Graduação

Função ou cargo ocupado: Professor Titular

Endereço completo para correspondência (bairro, cidade, estado, país e CEP)

Av. Unisinos, 950, sala 5A402d - Bairro Cristo Rei, São Leopoldo, Brasil, 930222-000

Telefones para contato: 51-3590.8186

e-mail: cd@unisinos.br

Nome completo: Peter Bent Hansen 
Filiação institucional: Programa de Pós-Graduação em Administração (PPGAd) da Pontifícia Universidade Católica do Rio Grande do Sul (PUCRS)

Departamento: Faculdade de Administração, Contabilidade e Economia (FACE)

Função ou cargo ocupado: Professor Adjunto

Endereço completo para correspondência (bairro, cidade, estado, país e CEP)

Av. Ipiranga, 6681, prédio 50, 11 . Andar, sala 1105 - Bairro Partenon, Porto Alegre, Brasil, CEP 90.619-900

Telefones para contato: 51-3320-3524

e-mail:peter.hansen@pucrs.br

Enviado em: 08/02/2011

Aprovado em: 26/09/2011 